\title{
Reflecting on the lessons learned in Bologna: Surgery of the Thoracic Aorta
}

\author{
Mohamad Bashir ${ }^{1}$, Matti Jubouri ${ }^{2}$, Davide Pacini ${ }^{3}$, Roberto di Bartolomeo ${ }^{3}$ \\ ${ }^{1}$ Vascular and Endovascular Surgery, Velindre University NHS Trust, Health Education and Improvement Wales (HEIW), Cardiff, Wales, UK; ${ }^{2}$ Hull \\ York Medical School, University of York, York, UK; ${ }^{3}$ Cardiac Surgery Department, Policlinico di Sant'Orsola, Alma Mater Studiorum Università di \\ Bologna, Italy \\ Correspondence to: Dr. Mohamad Bashir, MD, PhD, MRCS. Vascular and Endovascular Surgery, Velindre University NHS Trust, Health Education \\ and Improvement Wales (HEIW), Cardiff CF15 7QQ, UK. Email: drmobashir@outlook.com.
}

Received: 27 December 2021; Accepted: 28 January 2022; Published: 20 January 2023.

doi: 10.21037/jovs-21-68

View this article at: https://dx.doi.org/10.21037/jovs-21-68

The European Association of Cardio-Thoracic Surgery (EACTS) Aortic Forum took place in Bologna, Italy on the $15^{\text {th }}$ and $16^{\text {th }}$ of November 2021. This global meeting brought together the world's leaders in the field of aortovascular surgery to exchange expertise, debate complex high-risk surgical techniques on the body's largest artery, and share expert opinions, interesting case reports, and cutting-edge research. Following the forum, a series of eight case reports were published as part of the Best Video Presentation Prize for the 10th Postgraduate Course on "Surgery of the Thoracic Aorta" in Bologna. These case reports discussed a variety of interesting topics and detailed novel approaches to challenging cases, all of which will be highlighted in this editorial.

Albertini et al. (1) described their experience with aortic valve neocuspidization with glutaraldehyde-treated autologous pericardium in a severely obese 57 -year-old female patients with history of acute articular rheumatism in her childhood, who rapidly showed signs of dyspnoea and angina following moderate physical exertion a month prior to the operation. Transthoracic echocardiography (TTE) revealed severe aortic stenosis, which was later confirmed by transesophageal echocardiography (TEE). It is also worth noting that there was no coronary artery stenosis on computed tomography (CT) angiography. Although aortic valve replacement and mitral valve debridement was initially indicated, the patient's characteristics posed her at a high risk of prosthesis-patient mismatch regardless of which type of valve is implanted. Aortic valve neocuspidization with glutaraldehyde-treated autologous pericardium, developed by Ozaki, was used in this atypical patient to avoid the prosthesis-patient mismatch. Intraoperative TTE showed successful valve reconstruction and the patient had an uneventful recovery and follow-up. The authors stated that this technique is a safe and effective treatment choice for aortic valve disease in non-elderly patients and is a feasible alternative to aortic valve replacement with biological or mechanical valve as well as the Ross procedure. Yet, randomized trials and larger observational studies are needed in the future to confirm these findings as evidence in the literature on use of autologous pericardium is currently limited (1).

An interesting case of total arch replacement (TAR) following infection of the endovascular repair graft was detailed by Lopez-Marco et al. (2). Three years ago, their 78-year-old patient who had a large aneurysm involving the distal arch and descending aorta was deemed too high risk for TAR and instead underwent endovascular repair of the aortic arch and descending aorta. However, 3-year later this stent-graft became infected and was urgently removed, TAR with frozen elephant trunk was immediately performed, and the patient had an uneventful recovery. The authors stated having a specialised multi-disciplinary team discussion at a high-volume centre plays a pivotal role in the success of complex aortic repairs (2).

Nakao et al. (3) reported on a 28-year-old male patient with Marfan's syndrome who underwent aortic root replacement (Bentall procedure) and TAR using a FROZENIX-open stent-graft frozen embryo transfer (FET) device for extensive aortic pathology (EAP). Radiography 
revealed annuloaortic ectasia, an aortic aneurysm in the distal thoracic aorta, a thoracoabdominal aortic (TAA) aneurysm, and mild aortic regurgitation. The patient complained of backache on postoperative day 8 which a chest computed tomography revealed to be an expansion of the descending aorta and pericardial effusion. As an impending rupture of the thoracic aortic aneurysm and cardiac tamponade, the patient urgently underwent thoracic endovascular aortic repair and pericardial window with an uneventful postoperative recovery. The authors stressed on the importance of close follow-up of all patients undergoing FET even though it's a favourable and effective procedure that offers a safe reintervention option with thoracic endovascular aortic repair (TEVAR) (3).

The case report by Kawatou et al. (4) highlighted their valve-sparing aortic root replacement and TAR experience in a 61-year-old patient with aortic root dilatation with aortic regurgitation. This patient previously had an ascending aortic replacement for acute aortic dissection and zone 0 TEVAR with the chimney stent graft into the brachiocephalic artery with a bypass between bilateral carotid arteries. The second surgery included removal of the chimney graft and the proximal part of the primary aortic stent graft, reconstruction of the distal aortic arch using Vascutek Siena ${ }^{\mathrm{TM}}$ Collared Branched Graft (Terumo Vascutek, Tokyo, Japan), and aortic root reconstruction with reimplantation with Gelweave ${ }^{\mathrm{TM}}$ Valsalva Graft (Terumo Vascutek, Tokyo, Japan). In addition to aforementioned aortic pathology, the patient also suffered from rupture of fenestration in the left coronary cusp which was repaired during the same operation using the free margin resuspension technique. The patient was complicationfree at 1-year follow-up. The authors emphasised the importance of securing a safe arterial cannulation site, matching the diameter of the stent graft and the artificial graft in anastomosis, ensuring that the timing of the root reconstruction is optimal, and the careful utilisation of TEVAR for aortic arch pathology (4).

Innovation lies at the heart of surgery as it represents one of the means by which surgery evolves and advances. Innovation was the highlight of Martin-Suarez et al. (5) case report as they illustrated their minimally invasive aortic valve replacement technique through an upper hemi-sternotomy using a novel suturing and knotting device that could facilitate surgery and minimise technical difficulties. The 65-year-old female patient presented with dyspnoea (NYHA Class II) and was diagnosed with a pathologic bicuspid aortic valve, with stenosis and prevalent regurgitation. Two new innovative tools were used, the first of which is composed of two handpieces that assist with suturing, RAM ${ }^{\circledR}$ and SEW-EASY ${ }^{\circledR}$ (LSI SOLUTIONS ${ }^{\circledR}$, Victor, NY, USA), while the second device, called CORKNOT $^{\circledR}$ (LSI SOLUTIONS ${ }^{\circledR}$, Victor, NY, USA), facilitates knotting. The authors also discussed the benefits of minimally invasive cardiac surgery (MICS) to patients as well as the potential for increased practice of MICS amongst surgeons with the introduction of such facilitative technology.

Another case report which featured a novel and innovative surgical technique being used is that by Park et al. (6). The authors detailed their TAA replacement using a 4-branch graft (GelsoftTM Coselli, Terumo Aortic, Inchinnan, UK) along with the novel technique of intercostal artery reimplantation. The technique was named by the authors themselves as "frontage graft" and involves anastomosing target intercostal arteries to an 8- or 10-mm graft which has both ends connected to the main aortic graft and runs parallel. This procedure was performed on a 42 -year-old female Marfan patient who had Crawford type II aneurysm. The same patient previously underwent valve-sparing aortic root replacement with TAR using classical elephant trunk for chronic type B dissection and aortic root aneurysm. It was concluded that this novel technique offers a safe and more versatile treatment modality for extensive TAAs with good patency rate of the target branches reported (6).

Robinson et al. (7) presented a very interesting case of coarctation of the aorta $(\mathrm{CoA})$ in a 50 -year-old male with history of hypertension who had previously underwent two surgeries, one at the age of 16 which was an extra-anatomic bypass of the CoA, and a more recent endovascular stenting of the coarctation due to stenosis of the bypass. The patient was diagnosed with a large pseudoaneurysm of the descending thoracic aorta and underwent open explantation of the prior bypass and thoracic stent via left thoracotomy, with resection of the coarctation and reconstruction with a 22-mm woven Dacron graft as well as an aorto-to-leftsubclavian bypass with a $12-\mathrm{mm}$ Dacron graft. The patient was well at 2-month follow-up, which showed that such a complex procedure can be safely performed with excellent outcomes at high-volume aortic centres (7).

Last but not least, Patel et al. (8) reported their experience with the Freestyle Stentless Porcine Valve (Medtronic, Fridley, MN, USA) which is an option for both isolated aortic valve replacement (AVR) and full aortic root replacement. It is a fact that failed Freestyle Stentless Porcine Valve explantation can be very challenging due 
to the adhesions forming between the valve and the native sinus tissue, this often necessitates an aortic root replacement along with the failed valve replacement. The authors demonstrated with two distinct cases that explantation of this durable and haemodynamically excellent and valve can be performed safety and effectively with optimum results. A nicely detailed description of the surgical approach taken in each case is included (8).

In conclusion, reflecting on the lessons learned from the 10th Postgraduate Course on "Surgery of the Thoracic Aorta" in Bologna will be pivotal in paving the way for advanced developments in the field of aortovascular surgery. These valuable pieces of research will help set a clear direction for future research that will influence a real positive change in the clinical practice of aortovascular surgery to provide optimal care to patients.

The full versions of all the above case reports can be found at: https://jovs.amegroups.com/post/view/best-videopresentation-prize-for-the-10th-postgraduate-course-onldquo-surgery-of-the-thoracic-aorta-rdquo-in-bologna

\section{Acknowledgments}

Funding: None.

\section{Footnote}

Provenance and Peer Review: This article was commissioned by the editorial office, Fournal of Visualized Surgery for the series "Best Video Presentation Prize for the 10th Postgraduate Course on 'Surgery of the Thoracic Aorta' in Bologna". The article did not undergo external peer review.

Conflicts of Interest: All authors have completed the ICMJE uniform disclosure form (available at https://jovs. amegroups.com/article/view/10.21037/jovs-21-68/coif). The series "Best Video Presentation Prize for the 10th Postgraduate Course on 'Surgery of the Thoracic Aorta' in Bologna" was commissioned by the editorial office without any funding or sponsorship. $\mathrm{MB}, \mathrm{DP}$ and $\mathrm{RDB}$ served as the unpaid Guest Editors of the series. The authors have no other conflicts of interest to declare.

Ethical Statement: The authors are accountable for all aspects of the work in ensuring that questions related to the accuracy or integrity of any part of the work are appropriately investigated and resolved.
Open Access Statement: This is an Open Access article distributed in accordance with the Creative Commons Attribution-NonCommercial-NoDerivs 4.0 International License (CC BY-NC-ND 4.0), which permits the noncommercial replication and distribution of the article with the strict proviso that no changes or edits are made and the original work is properly cited (including links to both the formal publication through the relevant DOI and the license). See: https://creativecommons.org/licenses/by-nc-nd/4.0/.

\section{References}

1. Albertini A, Raviola E, Zucchetta F, et al. Aortic valve neocuspidization with glutaraldehyde-treated autologous pericardium to avoid the prosthesis-patient mismatch of a severely obese 57-year-old patient-a case report. J Vis Surg 2022;8:24.

2. Lopez-Marco A, Jahangeer S, Adams B, et al. Arch replacement following endovascular arch repair for an infected stent: case report. J Vis Surg 2022;8:9.

3. Nakao T, Tsuda S, Kume N, et al. Rapid expansion of the descending aorta following total arch replacement with a FROZENIX-open stent-graft for thoracic aortic aneurysm in a patient with Marfan syndrome: a case report. J Vis Surg 2022;8:25.

4. Kawatou M, Minatoya K, Yamazaki K, et al. A case report of valvesparing aortic root replacement in a patient with full metal jacket aorta. J Vis Surg 2022;8:26.

5. Martin-Suarez S, Mariani C, Murana G, et al. New tools in minimal invasive aortic valve surgery: case report. J Vis Surg 2022;8:29.

6. Park KH, Lee JH. Thoracoabdominal aorta replacement with branched graft for visceral and segmental artery reimplantation-case report. J Vis Surg 2022;8:27.

7. Robinson NB, Farrington WJ, Maresca P, et al. Reoperative repair of adult aortic coarctation with explantation of thoracic stent-graft: a case report. J Vis Surg 2022;8:8.

8. Patel PM, Chen EP. Challenging surgical management of failed freestyle stentless porcine valve: two case reports. J Vis Surg 2022;8:28.

doi: $10.21037 /$ jovs-21-68

Cite this article as: Bashir $M$, Jubouri $M$, Pacini D, di Bartolomeo R. Reflecting on the lessons learned in Bologna: Surgery of the Thoracic Aorta. J Vis Surg 2023;9:1. 